\title{
Seepage-Stress Coupling Analysis of Water-Rich Loess Tunnel
}

\author{
Zhijie Sun ${ }^{1, a}$, Jun Zhang ${ }^{1, b}$, Zhongming Su ${ }^{1, c}$ and Xiaohui Xue ${ }^{1, d}$ \\ Key Lab of Highway Construction \& Maintenance Technology in Loess Region, Shanxi \\ Transportation Research Institute, Shanxi, Taiyuan, 030006

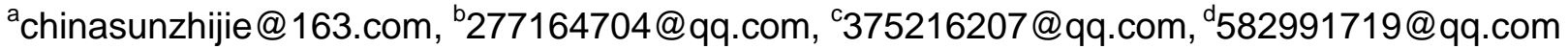

Keywords: Seepage-stress coupling; Water-rich; Loess tunnel; Grouting-reinforcement;

Abstract. Through engineering example and using the FEM software GTS, water-rich loess tunnel excavation is analyzed without or with the grouting-reinforcement effect and different permeability coefficient of grouting-reinforcement structure. Influence of flow field characteristics and displacement field characteristics caused by variation of grouting-reinforcement structure permeability coefficient in ordinary water level was analyzed. The results show that the permeability coefficient of grouting-reinforcement structure is play an important in the seepage path, pore water pressure and seepage velocity. It also influence in the displacement of surrounding rock. Designs of grouting-reinforcement structure of water-rich loess tunnel should consider impact of seepage-stress coupling effect. First, the waterproofing effect of grouting-reinforcement structure should be considered to, otherwise, it should avoid that the pore water pressure increasing by increase of waterproofing effect of grouting-reinforcement structure, the soil shear strength reducing.

\section{Introduction}

The process of water rich loess tunnel excavation, seepage phenomenon is more serious, from the face of water seeping under the action of gravity eventually remitted to the lowest point of the invert operation, continue to collect under the water caused the softening of Loess basement. The bearing capacity of the substrate is reduced.

In the tunnel construction, the two stress field is formed, and the changes of the groundwater balance in the original soil, which cause the change of the seepage field distribution and the stress distribution of the original stress field. Therefore, when the water level is below the loess tunnel construction, the water environment in the tunnel is not to be ignored, the influence of the seepage on the displacement field of the tunnel should be considered.

At present, there is little research on the coupling of seepage and stress in the loess area, and the water sensitivity of the loess is the most unfavorable factor for the engineering rock and soil. Based on this, this paper takes a two lane water rich loess tunnel as the research object, and the stress boundary conditions of tunnel excavation are closely linked with the boundary conditions of groundwater seepage and seepage. The influence of grouting and the soil permeability on the seepage field and the displacement field of the surrounding rock is analyzed by the effect of the combined action of groundwater seepage and soil stress.

\section{Numerical Modeling}

Plate elements simulate primary support of sprayed concrete. Plate elements simulate surrounding rocks and reinforced area. Beam elements simulate bolts. The numerical model is as follow in Fig.1. 


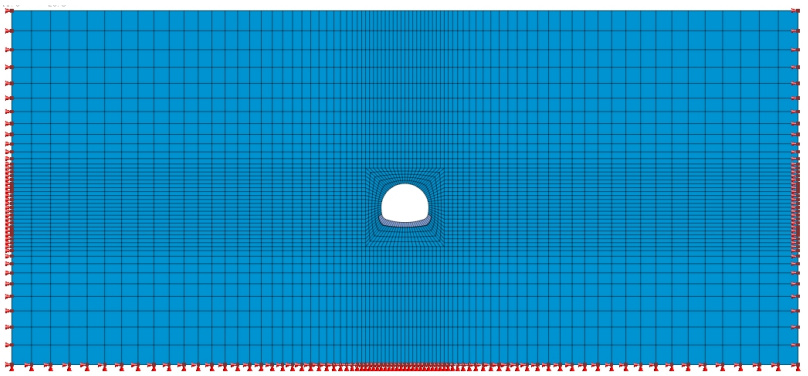

Fig.1 Two-dimensional percolation - stress grid chart

The constitutive model for rock and reinforced rock are all Mohr-Coulomb models. The primary support of sprayed concrete is elastic material. All material parameters are shown in Tab.1.

Tab.1 Material Parameters in Model

\begin{tabular}{|c|c|c|c|c|c|}
\hline Material & Modulus(GPa) & Poisson's & $\begin{array}{l}\text { Density } \\
\left(\mathrm{kg} / \mathrm{m}^{3}\right)\end{array}$ & Cohesive(kPa) & $\begin{array}{l}\text { Internal friction } \\
\text { angle }\left({ }^{\circ}\right)\end{array}$ \\
\hline Class V Rock & 0.15 & 0.3 & 2120 & 91.8 & 35.24 \\
\hline Reinforced Rock & 1 & 0.25 & 2300 & 200 & 45 \\
\hline Primary Support & 27.4 & 0.2 & 2332.84 & - & - \\
\hline \multicolumn{6}{|c|}{$\begin{array}{l}\text { The effect of the water resistance of the reinforcement is by adjusting the permeability } \\
\text { coefficient of the reinforcement region. The permeability coefficient of the reinforcement zone in } \\
\text { different working conditions is shown in table } 2 \text {. } \\
\text { Table } 2 \text { Permeability coefficient in different working conditions }(\mathrm{m} / \mathrm{h})\end{array}$} \\
\hline & II & III & IV \\
\hline \multicolumn{2}{|c|}{ permeability coefficient } & & $1 \times 10^{-3}$ & $1 \times 10^{-4}$ & $1 \times 10^{-5}$ \\
\hline \multicolumn{2}{|c|}{ Compared with the soil } & & $1 \%$ & $1 \%$ & $0.1 \%$ \\
\hline
\end{tabular}

\section{Analysis Results}

The distribution of the seepage path of the key points in the tunnel is shown in Figure 2 in different working conditions.

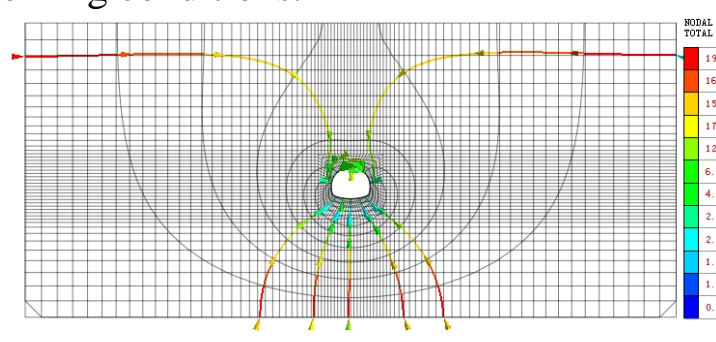

(a) No reinforcement

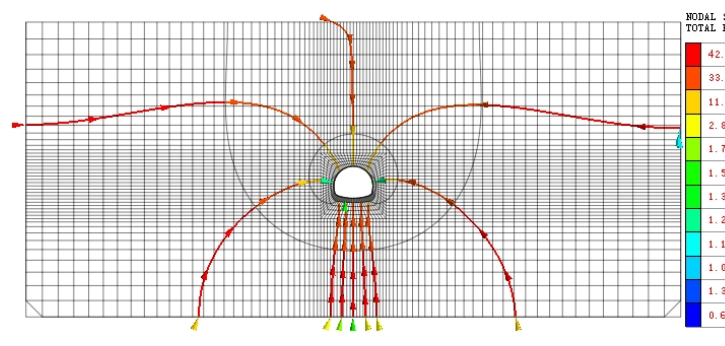

(c) $\mathrm{k}=1 \times 10^{-3}$

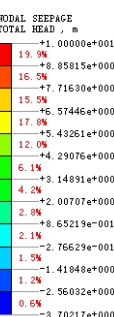

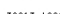

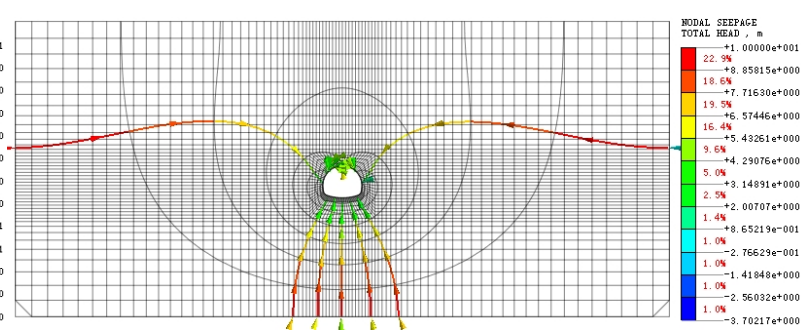

(b) $\mathrm{k}=1 \times 10^{-2}$

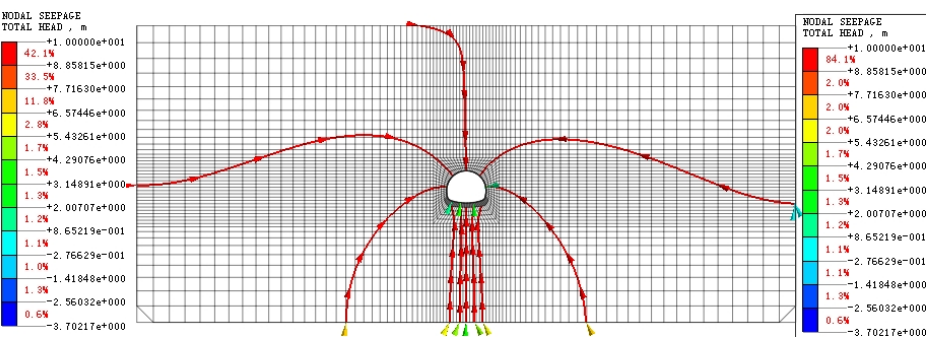

Fig.2 Seepage path distribution map

When there is no external surrounding rock reinforcement or solid permeability, the arch does not supply water body, when the permeability coefficient decreases to a certain extent, the dome 
water from above ground into seepage; without reinforcement, the arch foot water from both sides of the deep water supply, and the arch foot by $40 \mathrm{~m}$ deep water level, when the penetration coefficient decreases to a certain degree.

In Figure 2, there is no reinforcement and solid permeability to the tunnel arch in the way of the impact is greater than the inverted arch.

The distribution of pore pressure is shown in figure 3 in different working conditions.

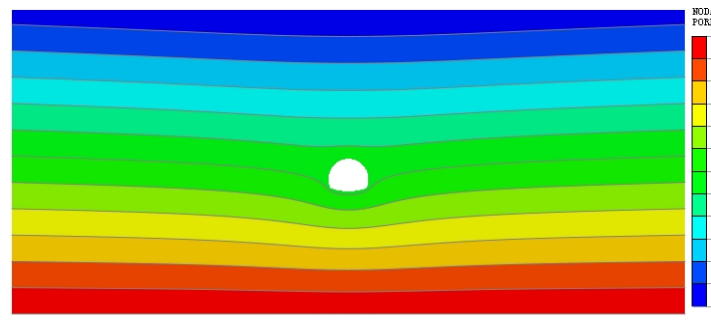

(a) No reinforcement

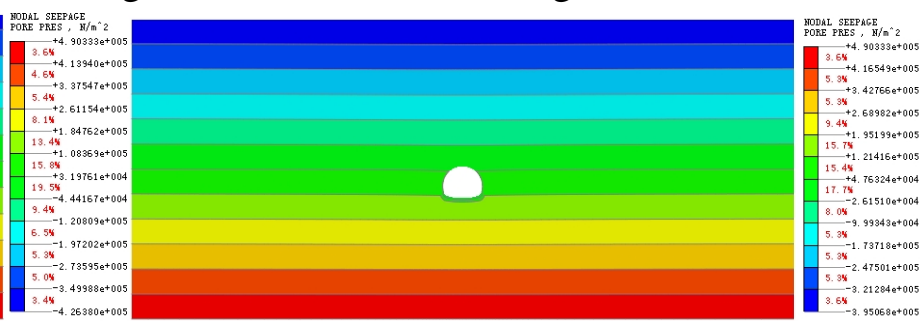

(b) $\mathrm{k}=1 \times 10^{-5}$

Fig.3 Pore water pressure distribution map

The influence of the permeability of the solid on the pore water pressure of the rock around the hole is relatively large. When the surrounding rock reinforcement, groundwater from the cavern clearance timely discharge of pore water pressure in the surrounding, the contour is broken in the parallel trend around the cavern, as shown in Figure 3 (a). In the case that the effect of water resistance is good (and the coefficient of the solid is small), the solid can effectively block the groundwater flow path, and the equivalent line of pore water pressure tends to parallel lines, as shown in Figure 3 (b). The pore water pressure decreases with the increase of the initial branch permeability.

Flow velocity distribution in different working conditions is shown in figure 4.

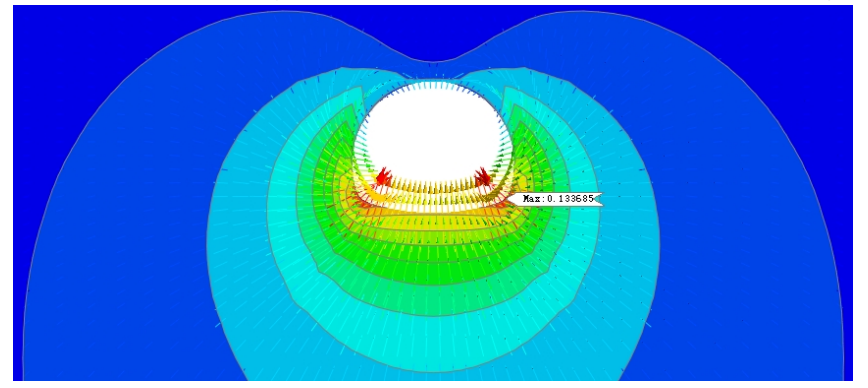

(a) No reinforcement

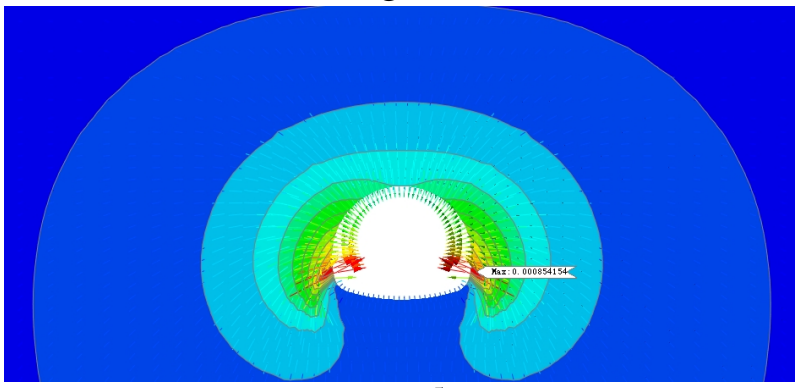

(b) $\mathrm{k}=1 \times 10^{-5}$

Fig.4 Seepage velocity distribution map (mete per hour)

In Figure 4, when the surrounding rock is not reinforced, the larger seepage flow velocity distribution in the inverted arch, the most value in the arch foot of the arch is $0.134 \mathrm{~m} / \mathrm{h}$. The maximum flow velocity direction is the vault direction. After the wall rock reinforcement, the maximum seepage flow velocity still appears in the arch foot of the inverted arch, with the decrease of the permeability coefficient, the maximum flow rate is 0.15 mete per hour, 0.055 mete per hour and 0.0085 mete per hour. Because of the late two grouting reinforcement, the effect of the water resistance of the inverted arch is stronger than the other parts. With the increase of the solid permeability coefficient, the flow velocity of the side wall and the arch part is heavy, and the flow velocity of the side wall and the arch is gradually reduced. 


\section{Conclusions}

Through engineering examples, using the finite element software, the coupling effect of seepage and stress in the excavation process of the two lane highway tunnel is studied. The influence of solid permeability coefficient on the seepage field and the displacement field of surrounding rock is analyzed. The results show that the permeability of the surrounding rock of the hole has a great influence on the flow path, the pore water pressure and flow velocity of the surrounding rock, and the vertical displacement of the surrounding rock is also affected.

There is no reinforcement and solid permeability to the tunnel arch in the way of the flow path is greater than the arch.

Due to the back of the arch part of the late two grouting reinforcement, the back arch part of the water resistance effect is stronger than other parts. With the increase of the solid permeability coefficient, the flow velocity of the side wall and the arch part is heavy, and the flow velocity of the side wall and the arch is gradually reduced.

The vault settlement decreases with the decrease of the increase of the permeability coefficient of the solid, and increases with the decrease of the increase of the penetration coefficient. The permeability coefficient decreases to a certain extent, and the influence of the displacement of the surrounding rock is weakened.

\section{Acknowledgements}

This work was financially supported by the Shanxi Traffic Science and Research Project (Research and Application of Supporting Structure Mechanical Properties of Large Section of Loess Tunnel), (2012-1-1).

\section{References}

[1] Hongyue Zhan and Qicai Wang: Journal of Water Resources Architectural Engineering. Vol.7(4) (2009), p. 117-120.

[2] China Merchants Chongqing Communications Research \& Design Institute: Code for Design of Highway Tunnel (JTG D70-2004) (China Communications Press publications, Beijing 2004).

[3] Xue Fu-chun, Ma Jian-lin, Yan Li-ping, et al: Journal of Vibration and Shock. Vol. 29(2) 2010, p. 202-207.

[4] Pang Xin-gang. Shanxi Science \& Technology of Communications. Vol. (224) (2013), p.33-34.

[5] Li Yu-ping. Hihgway Tunnel, Vol.(71) (2010), p. 31-33.

[6] Wang Daoliang, Liu Xinrong, Chen Shanquan, et al. Journal of Xihua University(Natural Science). Vol. 30(5) (2011), p.106-109.

[7] Du Chao-wei, Wang Meng-shu, Tan Zhong-sheng. Chinese Journal of Rock Mechanics and Engineering. Vol. 30(S2) (2011), p. 3567-3573.

[8] WEI Gang, GUO Zhiwei, WEI Xin-jian, et al. Rock and Soil Mechanics. Vol. 31(S1) (2010), p. 383-387. 